\title{
A Prospect-Theoretical Interpretation of Momentum Returns
}

\author{
Lukas Menkhoff, University of Hannover, Germany \\ and \\ Maik Schmeling, University of Hannover, Germany *
}

\author{
Discussion Paper 335 \\ May 2006 \\ ISSN: 0949-9962
}

\begin{abstract}
:
The puzzling evidence of seemingly high momentum returns is related to an understanding of risk as a simple covariance. If we consider, however, risk in higher-order statistical moments, momentum returns appear less advantageous. Thus, a prospect-theoretical assessment of US stock momentum returns provides a possible direction for explaining this puzzle.
\end{abstract}

JEL-Classification: $\quad$ G 11, G 12, G 14

Keywords: momentum trading, market efficiency, prospect theory

* We would like to thank an anonymous referee for helpfully providing us the data used in the final version of this research, many useful comments and suggestions. We are also grateful to Tarun Chordia for providing us the data that has been used in an earlier version of this paper.

Corresponding: Lukas Menkhoff, Department of Economics, University of Hannover, Königsworther Platz 1, D-30167 Hannover, Germany, menkhoff@gif.uni-hannover.de 


\section{A Prospect-Theoretical Interpretation of Momentum Returns}

\section{Introduction}

According to standard theory, returns on investment strategies might be higher than returns on holding the market portfolio if they carry a higher systematic risk. It is therefore surprising that simple momentum investment strategies seem to contradict this conventional wisdom by offering high returns that are not explained by conventional risk factors. The challenge to traditional capital market theory is particularly bold as momentum strategies are extremely simple by just buying those assets which performed best in the past reference period and selling short the worst performing assets. Thus momentum strategies do not require any fundamental understanding of asset markets and also no effort to forecast future returns. Despite this effrontery to capital market theory, the observation of highly significant momentum returns in the US stock market (Jegadeesh and Titman, 1993) was abundantly confirmed (e.g., Jegadeesh and Titman, 2001) and extended to other markets as well (Rouwenhorst, 1998). Thus, momentum returns represent a fascinating puzzle.

We contribute towards a possible understanding of high momentum returns by following the analytical perspective suggested by Benartzi and Thaler (1995). ${ }^{1}$ We find, indeed, that risk considerations as implemented by prospect theory might be a key: the prospect utility of US stock momentum returns is not higher than that of a comparable market portfolio. Therefore, prospect theory provides a possible direction for explaining the puzzle.

We proceed as follows: Section 2 introduces data and the puzzling multi-factor interpretation of US stock momentum returns. Section 3 demonstrates the riskiness of momentum and market returns by highlighting the higher-order statistical moments. Section 4 consequently presents the application of prospect theory to the momentum and market strategies respectively. Section 5 concludes.

\section{Data and the multi-factor interpretation of momentum returns}

We use data on the US stock market from July 1963 to December 2005. This monthly data set comprises the CRSP market return, the risk free rate, the market excess return and momentum returns from NYSE-AMEX stocks. The construction of momentum returns follows

\footnotetext{
${ }^{1}$ The failure of traditional models to explain the puzzling findings has stimulated a large body of behavioral models which inter alia include Barberis et al. (1998), Daniel et al. (1998) and Hong and Stein (1999).
} 
the method employed in Fama and French (1996). Stocks are ranked into deciles based on their returns in the formation period over the last year. Decile portfolios are equally weighted and momentum returns are obtained by taking a long position in the stocks of the tenth decile (P10) and shorting stocks in the first decile (P1). Portfolios are rebalanced monthly and one month is skipped between the end of the formation and the beginning of the holding period. The holding period is one month.

At the core of the momentum puzzle is the fact that this strategy is self-financing and has a significantly positive mean return, which does not seem to be compensating for any kind of conventional measure of risk. Neither traditional beta-factors nor multi-factor analyses inspired by Fama and French have been successful in capturing momentum returns (see Fama and French, 1996, Grundy and Martin, 2001). Consider for example the popular Fama-French three factor model that "explains" returns by their exposure to three risk factors. A time-series regression using GMM applied to our data leads to the following result

$$
\begin{aligned}
& \mathrm{MOM}_{\mathrm{t}}=1.50-0.24 \mathrm{ER}_{\mathrm{t}}-0.02 \mathrm{SMB}_{\mathrm{t}}-0.21 \mathrm{HML}_{\mathrm{t}}, \mathrm{R}^{2} \approx 1 \% \\
& {[3.05] \quad[-1.99] \quad[-0.13] \quad[-1.17]}
\end{aligned}
$$

with t-statistics in parentheses and MOM, ER, SMB and HML denoting monthly momentum returns, market returns in excess over the risk free rate and the SMB (size) and HML (leverage) factor, respectively. As can be directly inferred, a conventional momentum strategy yields risk adjusted returns of about one and a half per cent each month over the whole sample of 42 years. A similar conclusion can be drawn from using a simple one factor market model. Seen from the viewpoint of these models, momentum strategies offer a free lunch.

\section{Comparing statistics of market and momentum returns}

Linear factor models look at first and second-order (cross-)moments of return distributions. However, there is a tendency in economics and finance to consider more complex and in particular asymmetric approaches to measure risk (see e.g. Ang, Chen and Xing, 2005). Therefore, let us take a look at the return distributions of market excess ${ }^{2}$ and momentum returns as shown in Table 1 for both monthly returns and rolling 12-months returns. Unconditional average monthly returns of the momentum portfolio are about 1.29 percent p.m. and therefore somewhat lower compared to the intercept of 1.5 percent in (1). However, a t-test employing Newey-West standard errors yields a test statistic of 2.45 for the null of mean zero when applied to raw momentum returns. Less advantageous for the momentum strategy is the fact that

\footnotetext{
${ }^{2}$ The market excess return over the risk free rate is an appropriate benchmark for momentum returns since it can be thought of representing an investment strategy that uses short-term loans to finance the market investment. This avoids to invest own capital and thus makes it comparable to momentum returns.
} 
both the standard deviation and the maximum one-month loss of the momentum portfolio of 55.84 percent are much higher than the same statistics of market excess returns. A further key to understanding riskiness is provided by the more negative skewness (see also Harvey and Siddique (2000) in this respect) of momentum returns and their higher kurtosis compared to market excess returns. Except for the skewness, the ordering of these statistics for the two portfolios is unchanged when using smoother 12-months returns.

Table 1. Descriptive statistics of momentum and market excess returns

\begin{tabular}{lrrrr}
\hline & \multicolumn{2}{c}{ Monthly returns (in \%) } & \multicolumn{2}{c}{ 12-months returns (in \%) } \\
& MOM & ER & MOM & ER \\
\cline { 2 - 5 } Mean & 1.29 & 0.47 & 17.01 & 5.63 \\
Median & 1.84 & 0.76 & 13.98 & 8.13 \\
Maximum gain & 31.91 & 16.05 & 204.77 & 54.17 \\
Maximum loss & -55.84 & -23.13 & -70.38 & -45.76 \\
Standard deviation & 10.77 & 4.42 & 43.25 & 16.00 \\
Skewness & -0.94 & -0.50 & 0.66 & -0.29 \\
Kurtosis & 5.89 & 5.06 & 4.32 & 2.98 \\
\hline
\end{tabular}

MOM and ER denote momentum returns and the market excess return over the risk free rate, respectively. 12-month returns are obtained by chaining monthly returns. The sample period is 1963:07 to $2005: 12$.

The higher maximum loss as well as the third and fourth-order statistical moments of the momentum return distribution are unattractive for loss averse investors since the latter weigh losses more heavily than gains of the same size. In this setting, and holding first and second order moments fixed, an increasingly negative skewness indicates that losses occur more often and an increasingly high kurtosis indicates that extreme return realizations become more likely. Both, negative skewness and higher kurtosis are clearly unattractive for loss averse investors.

\section{A prospect-theoretical interpretation of momentum returns}

As a way to consider loss aversion in investment decisions we follow Benartzi and Thaler's (1995) approach of myopic loss aversion which includes two modifications of the traditional capital market approach. First, they substitute the traditional symmetric risk-return approach by the empirically well established prospect theory (which incorporates loss aversion) to gauge the attractiveness of portfolio return distributions. Second, they take into account the fact that evaluation horizons of risky investments often do not span over decades but over months (in the case of fund managers) or a year (as sometimes assumed for private investors). Loss aversion in combination with short horizons leads to myopic loss aversion, a behavior which is increasingly confirmed by recent empirical evidence (e.g. Haigh and List, 
2005, or Bellemare et al., 2005). The impact of myopic loss aversion on investment behavior can be analyzed by using prospect theory. This theory provides an empirically well established approach to assess - among others - risk-return profiles of different portfolios. Moreover, the element of a reference point in prospect theory fits well with the notion of short horizons. Therefore, prospect utility seems to be a promising approach to directly compare US momentum returns with US market excess returns in terms of the investors' utility.

Regarding the exact methodology, we follow Benartzi and Thaler (1995), who evaluate stock and bond returns with a cumulative prospect utility function to find a behavioral explanation for the equity premium puzzle. The key to their analysis is the nonlinear value function, as proposed and estimated by Kahnemann and Tversky (1979) and Tversky and Kahnemann (1992) which has the following form:

$$
v(x)=\left\{\begin{array}{cc}
x^{\alpha} & \text { if } x \geq 0 \\
-\lambda(-x)^{\beta} & \text { if } x<0
\end{array}\right.
$$

where $\mathrm{v}$ is the value function, $\mathrm{x}$ denotes returns and $\lambda$ is the coefficient of loss aversion, which Tversky and Kahnemann (1992) estimate to be 2.25. The estimated values for $\alpha$ and $\beta$ are both 0.88 , creating a concave shape in the domain of gains and a convex shape for the value function in the domain of losses. This procedure models agents as risk-averse for positive and riskseeking for negative outcomes, relative to the reference point. Since the coefficient of loss aversion is larger than one, agents put more weight on losses than on gains of the same size.

The prospective utility is just the weighted sum of these values:

$$
\mathrm{V}(\mathrm{G})=\sum_{\mathrm{i}} \pi_{\mathrm{i}} \mathrm{v}\left(\mathrm{x}_{\mathrm{i}}\right)
$$

where $\pi_{\mathrm{i}}$ is a transformation of the probability $\mathrm{p}_{\mathrm{i}}$ of obtaining the $i$ th outcome. In cumulative prospect utility this transformation depends not only on $\mathrm{p}_{\mathrm{i}}$, but also on the probabilities of the other outcomes. Specifically, $\pi_{\mathrm{i}}$ can be computed by taking the difference of the weighted probability of obtaining an outcome at least as good as the $\mathrm{x}_{\mathrm{i}}\left(\right.$ denoted $\mathrm{P}_{\mathrm{i}}$ ) and the weighted probability of obtaining an outcome that is better than $\mathrm{x}_{\mathrm{i}}\left(\right.$ denoted $\left.\mathrm{P}^{*}\right)$, formally

$$
\pi_{\mathrm{i}}=\mathrm{w}\left(\mathrm{P}_{\mathrm{i}}\right)-\mathrm{w}\left(\mathrm{P}_{\mathrm{i}}^{*}\right)
$$

and the weight $\mathrm{w}$ is

$$
w(p)=\frac{p^{\gamma}}{\left(p^{\gamma}+(1-p)^{\gamma}\right)^{1 / \gamma}},
$$

with an estimated value for $\gamma$ of 0.61 and 0.69 for the domains of gains and losses respectively.

To perform the comparison of momentum and market excess returns over different horizons of evaluation, we simulate the return distributions of both strategies by drawing 
1,000,000 $n$-month returns (with replacement, $n=1,2, \ldots, 30$ ) from both return series and rank them in descending order. For each of these simulated distributions, one hundred intervals of 10,000 observations are formed and the mean return for each is computed. ${ }^{3}$ Using these returns, the prospective utility for both series and evaluation horizon is easily obtained.

In order to get more realistic results we further take into account transaction costs of the momentum strategy. These might well be substantial since the strategy demands portfolio adjustments each month and has to deal with comparatively large bid-ask spreads of small and illiquid stocks. The existing literature often employs no transaction costs (Jegadeesh and Titman, 2001) although Korajczyk and Sadka (2004) find costs of up to five percent.

Figure 1 plots the result of this simulation exercise for both the momentum (dashed lines) and market excess returns (solid line) for evaluation horizons ranging from one to 36 months and for transaction costs (for the momentum strategy) ranging from zero to ten percent p.a.. As can be expected, the lowest dashed line represents the cumulative prospective utility of the momentum strategy when transaction costs equal ten percent p.a. whereas the uppermost dashed line shows the prospective utility without transaction costs. Two implications of this figure stand out. First, similar to the results in Benartzi and Thaler (1995), all selffinancing stock portfolios only yield positive utility for evaluation horizons of about one year and beyond. Investors evaluating their portfolios more often are better off avoiding the two investment strategies under consideration here. ${ }^{4}$ Second, even for very moderate transaction costs of only one percent p.a., investors with evaluation horizons of more than two years do not prefer momentum portfolios to the self-financing market portfolio.

This is a possible explanation for the puzzling observation that momentum returns do not attract arbitrageurs who exploit this opportunity of seemingly risk free profits. The fact that prospective utility investors are loss averse prevents them from holding a momentum portfolio that has a more extreme return distribution than the comparable market portfolio. Although longer evaluation horizons tend to erase some of the skewness and kurtosis (see Table 1), a conventional momentum strategy does not clearly outperform the self-financing market portfolio in terms of the investors' utility over any reasonable evaluation horizon and for reasonable transaction costs.

\footnotetext{
${ }^{3}$ Effectively, this procedure proposed by Benartzi and Thaler (1995) simulates the distribution of returns and calculates mean returns conditional on observing an outcome in one of the hundred percentiles of the distribution. Note also, that we implement a finer grid than Benartzi and Thaler (1990) who use only twenty intervals.

${ }^{4}$ In our view, the fact that momentum portfolios are rebalanced monthly does not necessarily conflict with investors employing longer evaluation horizons for at least two reasons. First, rebalancing is a purely mechanical activity that does not force investors to evaluate the performance of their investment strategy. Second, momentum investing can be delegated to asset managers so there is no monthly activity on behalf on the investor at all.
} 
Figure 1. Prospective utility of momentum and market excess returns for different evaluation horizons and different transaction costs

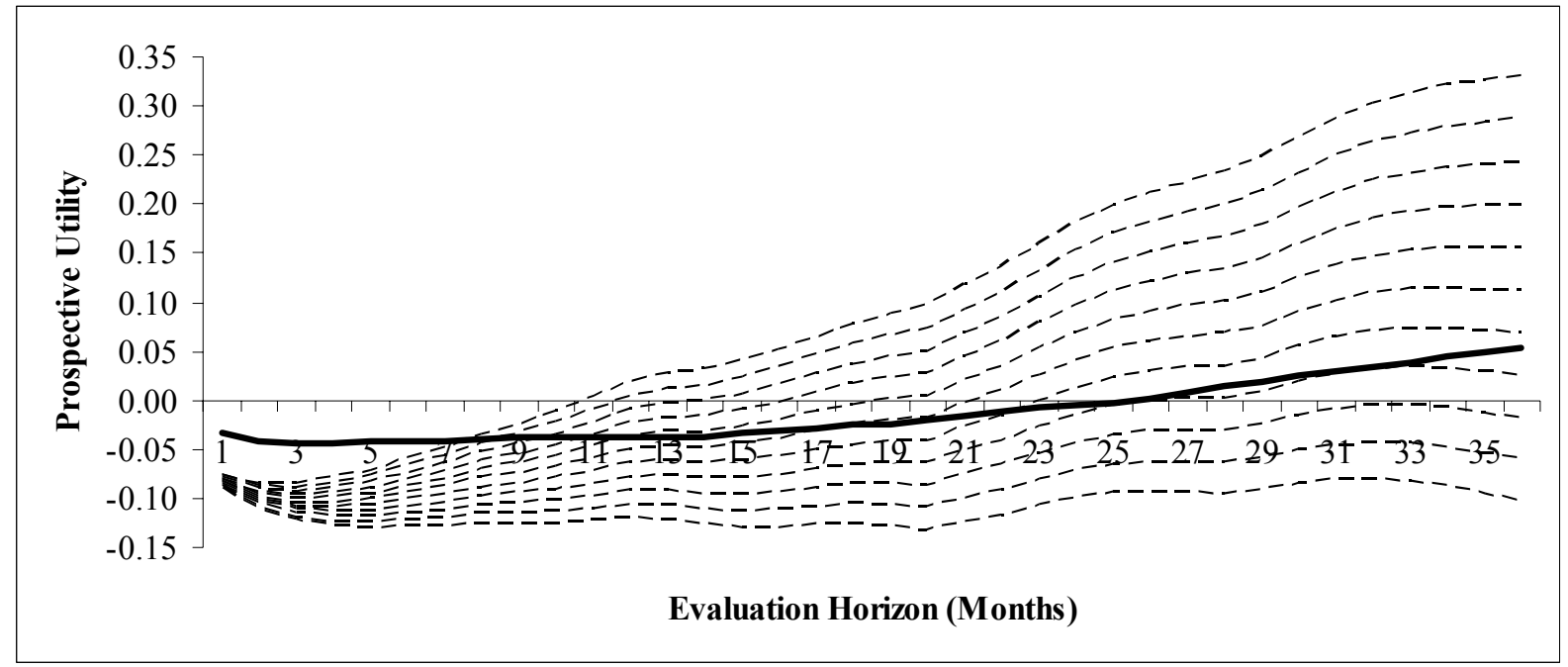

The horizontal axis displays the evaluation horizon under which prospective utility (vertical axis) is calculated and the vertical axis measures the cumulative prospective utility of an investment strategy. The solid line represents market excess returns (ER), whereas the dashed lines represent momentum returns (MOM) for annual transaction costs from zero to ten percent. The sample period is 1963:07 to 2005:12.

Figure 2 documents further analyses in the spirit of Benartzi and Thaler (1995). Panel (A) shows cumulative prospective utilities for different portfolio allocations of the momentum strategy and the self-financing market portfolio at a 12 months evaluation horizon. The different lines correspond to transaction costs of zero to ten percent p.a. As was shown in Figure 1, a pure momentum strategy yields a marginal positive utility at the 12 months horizon. Adding transaction costs, this utility becomes negative immediately. However, combining the momentum strategy with the self-financing market portfolio can improve utility. This is easily explained by the apparent lack of correlation between momentum and market excess returns as indicated in equation (1). However, the optimal share of the momentum portfolio ranges from 24 percent to 32 percent only and imposing transaction costs of more than seven percent p.a. does not yield positive utilities anymore. This clearly reduces the possibility to arbitrage momentum strategies.

Finally, Panel (B) of Figure 2 shows the implied momentum premium investors with evaluation horizons from one to fifteen years demand for holding the momentum portfolio. Again, the figure has intuitive appeal and is similar to the results in Benartzi and Thaler (1995). Leaving transaction costs aside, short-termism of investors demands a high momentum return of almost 16 percent p.a. in order to make this strategy attractive to investors with a one year evaluation horizon. Patient investors with an evaluation horizon of e.g. 15 years only de- 
mand a premium of about four percent p.a. to compensate for the higher order moment risk associated with momentum returns. ${ }^{5}$

Figure 2. Optimal portfolio allocation and implied momentum premium
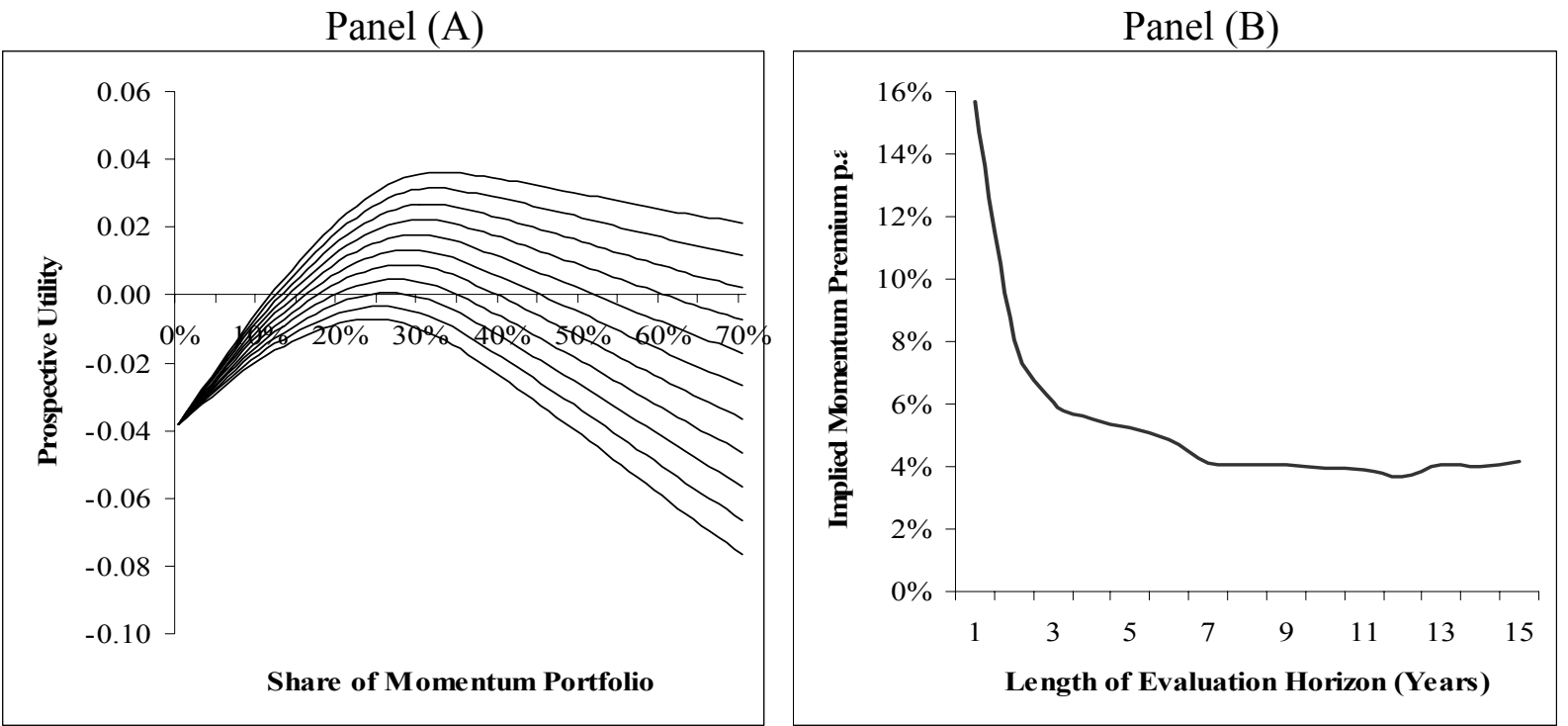

Panel (A) shows prospective utility (y-axis) for different portfolio shares (x-axis) of the momentum portfolio at a 12 months evaluation horizon. The lines correspond to transaction costs ranging from zero to ten percent p.a. The remaining portfolio share is allocated to the self-financing market portfolio. Panel (B) shows implied momentum premiums for evaluation horizons from one to fifteen years (no transaction costs imposed). The sample period is 1963:07 to 2005:12 for both panels.

\section{Conclusion}

The interpretation of US stock momentum returns over 42 years from the viewpoint of prospect theory suggests that loss adverse investors may be (partially) compensated for the higher probability of extreme losses and risk in higher order moments over reasonable evaluation horizons. Thus prospect theory seems to provide a fruitful access to analyze financial risks, which was shown earlier regarding portfolio choice (Berkelaar et al., 2004), the equity premium puzzle (Benartzi and Thaler, 1995 or Barberis et al., 2001) and is shown here regarding the puzzle of high momentum returns.

\section{References}

Ang, Andrew, Joseph Chen and Yuhang Xing (2005), Downside Risk, Review of Financial Studies, forthcoming.

Barberis, Nicholas, Ming Huang and Tano Santos (2001), Prospect Theory and Asset Prices, Quarterly Journal of Economics, 116, 1-53.

Barberis, Nicholas, Andrei Shleifer and Robert Vishny (1998), A Model of Investor Sentiment, Journal of Financial Economics, 49, 307-343.

\footnotetext{
${ }^{5}$ All results are qualitatively identical when using the popular UMD momentum data (available from Kenneth French's web site) over a period of 80 years or data for a strategy of a six months formation and six months holding period as applied in Chordia and Shivakumar (2002).
} 
Bellemare, Charles, Michaela Krause, Sabine Kröger and Chendi Zhang (2005), Myopic Loss Aversion: Information Feedback vs. Investment Flexibility, Economics Letters, 87, 319324.

Benartzi, Shlomo and Richard H. Thaler (1995), Myopic Loss Aversion and the Equity Premium Puzzle, Quarterly Journal of Economics, 110, 75-92.

Berkelaar, Arjan B., Roy Kouwenberg and Thierry Post (2004), Optimal Portfolio Choice under Loss Aversion, Review of Economics and Statistics, 86, 973-987.

Chordia, Tarun and Lakshmanan Shivakumar (2002), Momentum, Business Cycle, and Timevarying Expected Returns, Journal of Finance, 57, 985-1019.

Daniel, Kent, David Hirshleifer and Avanidhar Subrahmanyam (1998), Investor Psychology and Security Market Under- and Overreactions, Journal of Finance, 53, 1839-1885.

Fama, Eugene F. and Kenneth R. French (1996), Multifactor Explanations of Asset Pricing Anomalies, Journal of Finance, 51, 55-84.

Grundy, Bruce D. and J. Spencer Martin (2001), Understanding the Nature of the Risks and the Source of the Rewards to Momentum Investing, Review of Financial Studies, 14:1, 29-78.

Haigh, Michael S. and John A. List (2005), Do Professional Traders Exhibit Myopic Loss Aversion? An Experimental Analysis, Journal of Finance, 60:1, 523-534.

Harvey, Campbell R. and Akhtar Siddique (2000), Conditional Skewness in Asset Pricing Tests, Journal of Finance, 55, 1839-1886.

Hong, Harrison and Jeremy Stein (1999), A Unified Theory of Underreaction, Momentum Trading and Overreaction in Asset Markets, Journal of Finance, 54, 2143-218

Jegadeesh, Narasimhan and Sheridan Titman (1993), Returns to Buying Winners and Selling Losers: Implications for Stock Market Efficiency, Journal of Finance, 48:1, 65-91.

Jegadeesh, Narasimhan and Sheridan Titman (2001), Profitability of Momentum Strategies: An Evaluation of Alternative Explanations, Journal of Finance, 56, 699-720.

Kahneman, Daniel and Amos Tversky (1979), Prospect Theory: An Analysis of Decision under Risk, Econometrica, 47, 263-291.

Korajczyk, Robert A. and Ronnie Sadka (2004), Are Momentum Profits Robust to Trading Costs?, Journal of Finance, 59, 1039-1082.

Rouwenhorst, K. Geert (1998), International Momentum Strategies, Journal of Finance, 53:1, 267-284.

Tversky, Amos and Daniel Kahnemann (1992), Advances in Prospect Theory: Cumulative Representation of Uncertainty, Journal of Risk and Uncertainty, 5, 297-323. 


\section{Appendix to "A Prospect-Theoretical Interpretation of Momentum Returns"}

This appendix documents robustness of earlier findings by applying the identical method to two different, but popular momentum strategies. Appendix A shows results for the UMD momentum portfolio which is different from the earlier analysis in two important respects: first, the data period is much longer (including periods where momentum returns have been tentatively worse) and, second, winner and loser portfolios are formed by relying on the extreme 30 percent of stocks each, instead of ten percent. The formation period is 12 months. Data are taken from Kenneth French's web site and the sample is 1927:01 to 2004:12. Appendix B shows results for the strategy proposed by Jegadeesh and Titman (1993). Formation and holding period are 6 months both, and the strategy buys (sells) the top (bottom) decile of stocks. The sample period is 1961:01 to 1999:12 and data are from Chordia and Shivakumar (2002).

\section{Appendix A. UMD momentum strategy}

A1. Equation (1)

This equation shows results from regressing the monthly UMD momentum returns $\left(\mathrm{MOM}_{\mathrm{t}}\right)$ on a constant and the three risk factor model of Fama and French (1996) using GMM and NeweyWest standard errors. T-statistics are in parenthesis.

$$
\begin{aligned}
& \mathrm{MOM}_{\mathrm{t}}=1.12-0.21 \mathrm{ER}_{\mathrm{t}}-0.16 \mathrm{SMB}_{\mathrm{t}}-0.43 \mathrm{HML}_{\mathrm{t}}, \mathrm{R}^{2}=22.5 \% \\
& {[7.62] \quad[-2.77] \quad[-2.11] \quad[-3.08]}
\end{aligned}
$$

A2. Descriptive statistics of momentum and market excess returns

MOM and ER denote UMD momentum returns and the market excess return over the risk free rate, respectively. 12-month returns are obtained by chaining monthly returns. The sample period is 1927:01 to $2004: 12$.

\begin{tabular}{lrrrr}
\hline & \multicolumn{2}{c}{ Monthly returns (in \%) } & \multicolumn{2}{c}{ 12-months returns (in \%) } \\
& MOM & ER & MOM & \multicolumn{1}{c}{ ER } \\
\cline { 2 - 5 } Mean & 0.75 & 0.65 & 9.09 & 8.19 \\
Median & 0.94 & 0.98 & 9.97 & 8.63 \\
Maximum gain & 18.38 & 38.18 & 76.70 & 154.73 \\
Maximum loss & -50.92 & -29.03 & -75.80 & -66.43 \\
Standard deviation & 4.73 & 5.49 & 15.27 & 21.61 \\
Skewness & -3.00 & 0.21 & -1.06 & 0.43 \\
Kurtosis & 30.86 & 10.63 & 9.11 & 6.53 \\
\hline
\end{tabular}


A3. Prospective utility of momentum and market excess returns for different evaluation horizons and different transaction costs

The horizontal axis displays the evaluation horizon under which prospective utility (vertical axis) is calculated and the vertical axis measures the prospective utility of an investment strategy. The solid line represents market excess returns (ER), whereas the dashed lines represent UMD momentum returns (MOM) for annual transaction costs from zero to ten percent. The sample period is 1927:01 to 2004:12.

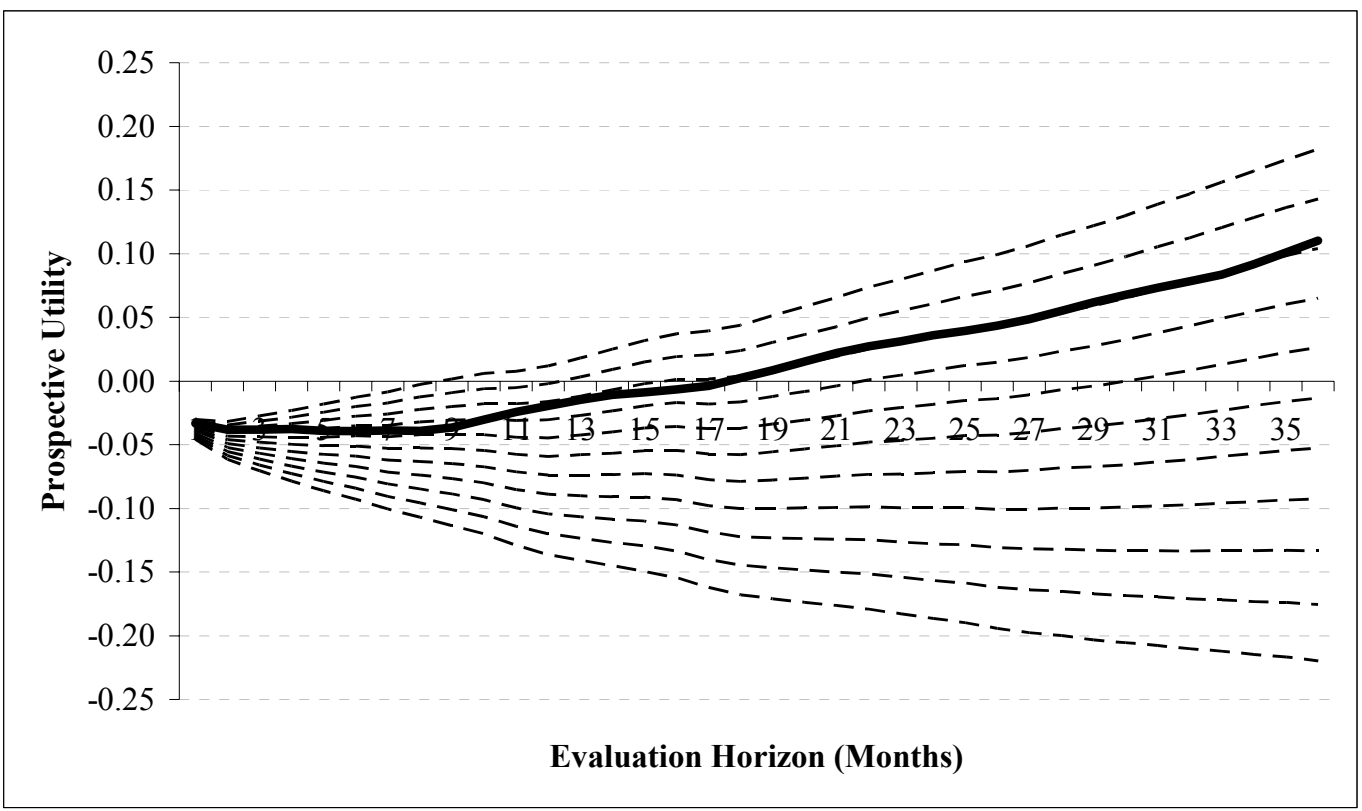


A4. Optimal portfolio allocation and implied momentum premium

Panel (A) shows prospective utility (y-axis) for different portfolio shares (x-axis) of the momentum portfolio at a 12 months evaluation horizon. The lines correspond to transaction costs ranging from zero to ten percent p.a. The remaining portfolio share is allocated to the self-financing market portfolio. Panel (B) shows implied momentum premiums for evaluation horizons from one to fifteen years (no transaction costs imposed).

Panel (A)

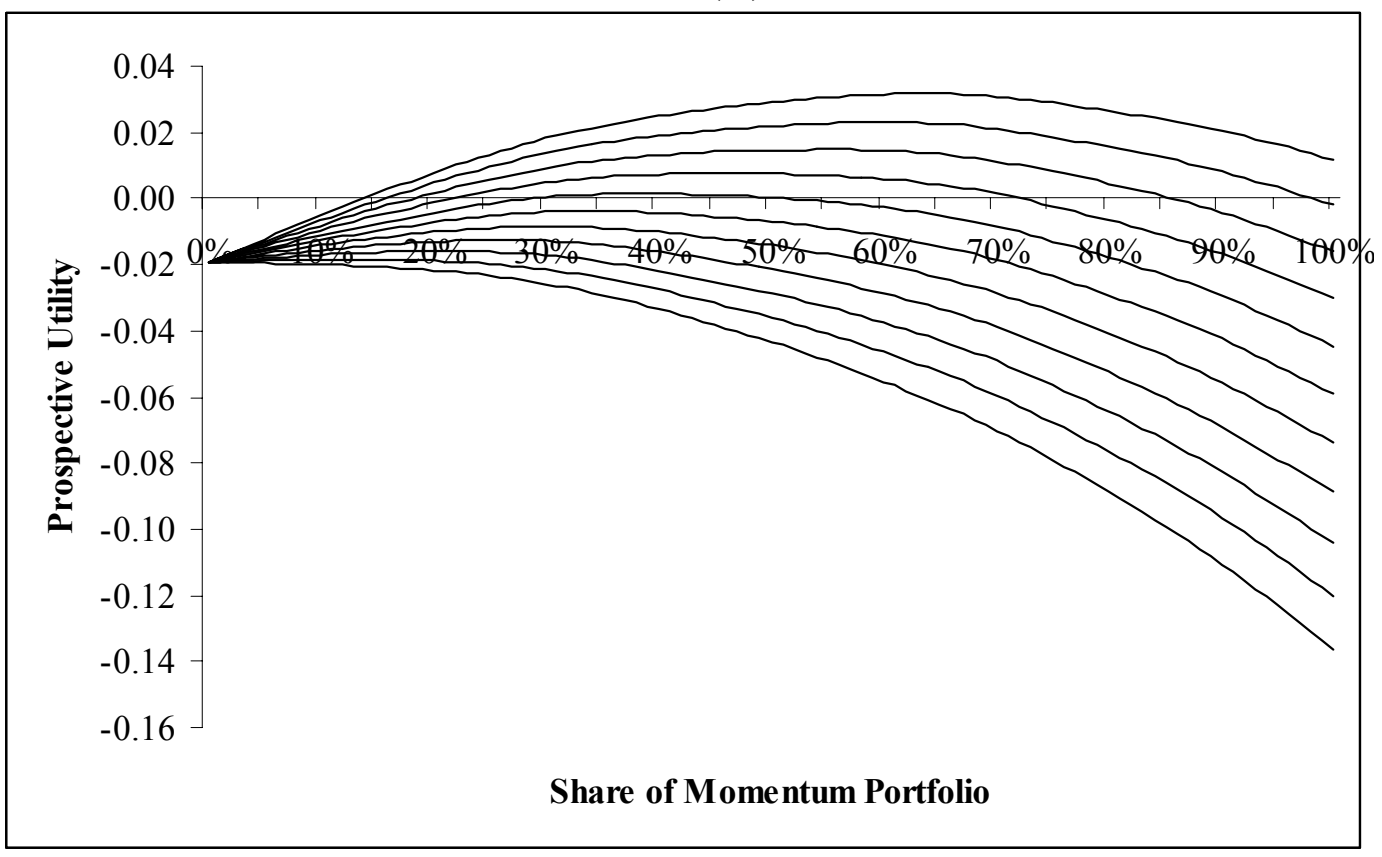

Panel (B)

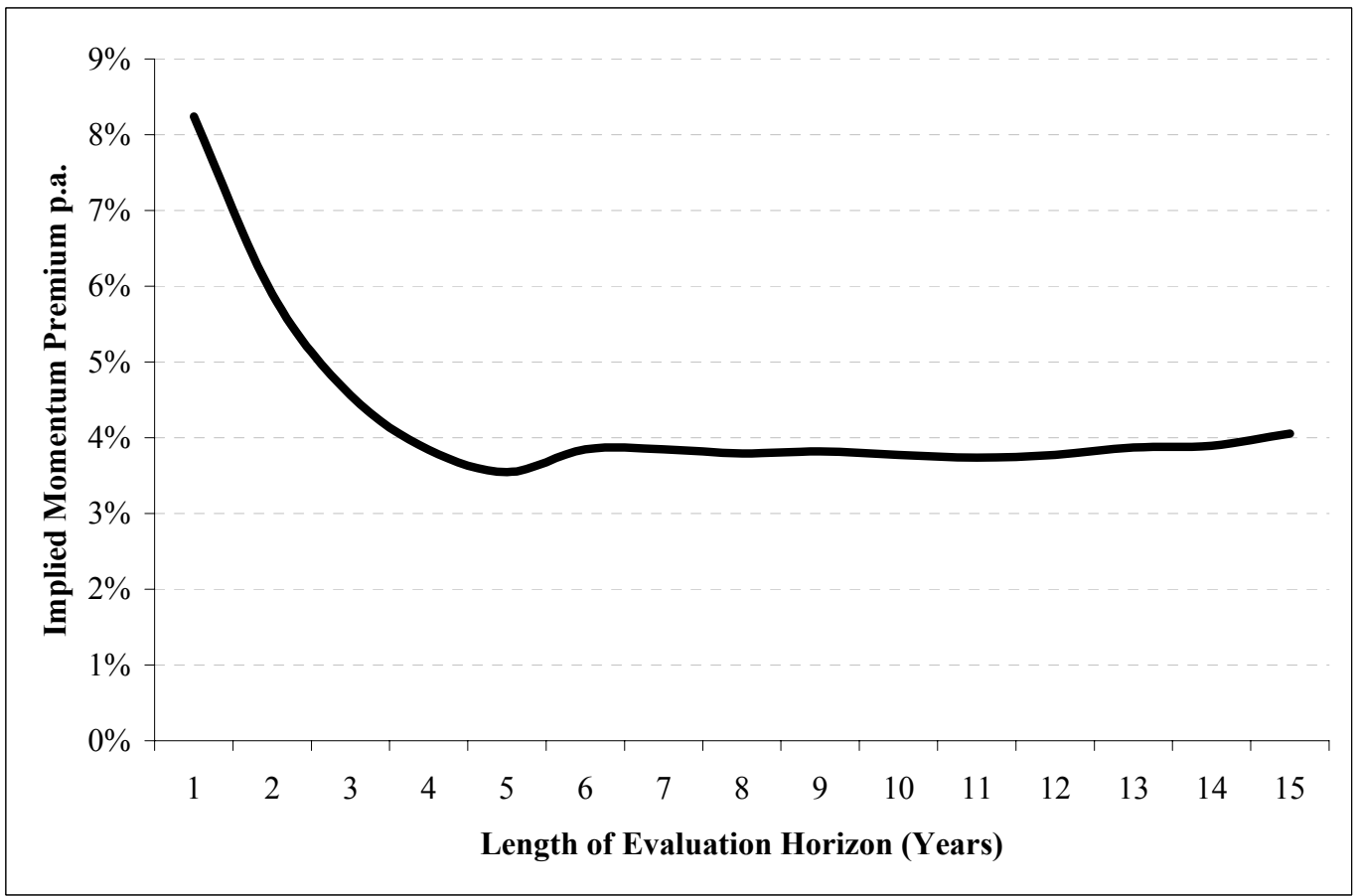




\section{Appendix B. Momentum strategy with a six months formation and holding period}

B1. Equation (1)

This equation shows results from regressing the monthly momentum returns $\left(\mathrm{MOM}_{\mathrm{t}}\right)$ on a constant and the three risk factor model of Fama and French (1996) using GMM and NeweyWest standard errors. T-statistics are in parenthesis.

$$
\begin{aligned}
& \mathrm{MOM}_{\mathrm{t}}=1.13-0.11 \mathrm{ER}_{\mathrm{t}}-0.69 \mathrm{SMB}_{\mathrm{t}}-0.52 \mathrm{HML}_{\mathrm{t}}, \mathrm{R}^{2}=17.64 \% \\
& {[5.79] \quad[-1.20] \quad[-3.71] \quad[-3.73]}
\end{aligned}
$$

B2. Descriptive statistics of momentum and market excess returns

MOM and ER denote momentum returns and the market excess return over the risk free rate, respectively. 12-month returns are obtained by chaining monthly returns. The sample period is 1961:01 to 1999:12.

\begin{tabular}{lrrrr}
\hline & \multicolumn{2}{c}{ Monthly returns (in \%) } & \multicolumn{2}{c}{ 12-months returns (in \%) } \\
& MOM & ER & MOM & \multicolumn{1}{c}{ ER } \\
\cline { 2 - 5 } Mean & 0.78 & 0.57 & 9.19 & 6.45 \\
Median & 1.39 & 0.83 & 10.96 & 8.49 \\
Maximum gain & 14.48 & 16.05 & 62.14 & 54.16 \\
Maximum loss & -36.52 & -23.13 & -46.32 & -45.76 \\
Standard deviation & 5.41 & 4.38 & 18.15 & 15.36 \\
Skewness & -2.64 & -0.51 & -0.50 & -0.33 \\
Kurtosis & 17.01 & 5.40 & 3.44 & 3.16 \\
\hline
\end{tabular}


B3. Prospective utility of momentum and market excess returns for different evaluation horizons and different transaction costs

The horizontal axis displays the evaluation horizon under which prospective utility (vertical axis) is calculated and the vertical axis measures the prospective utility of an investment strategy. The solid line represents market excess returns (ER), whereas the dashed lines represent momentum returns (MOM) for annual transaction costs from zero to ten percent. The sample period is 1927:01 to 2004:12.

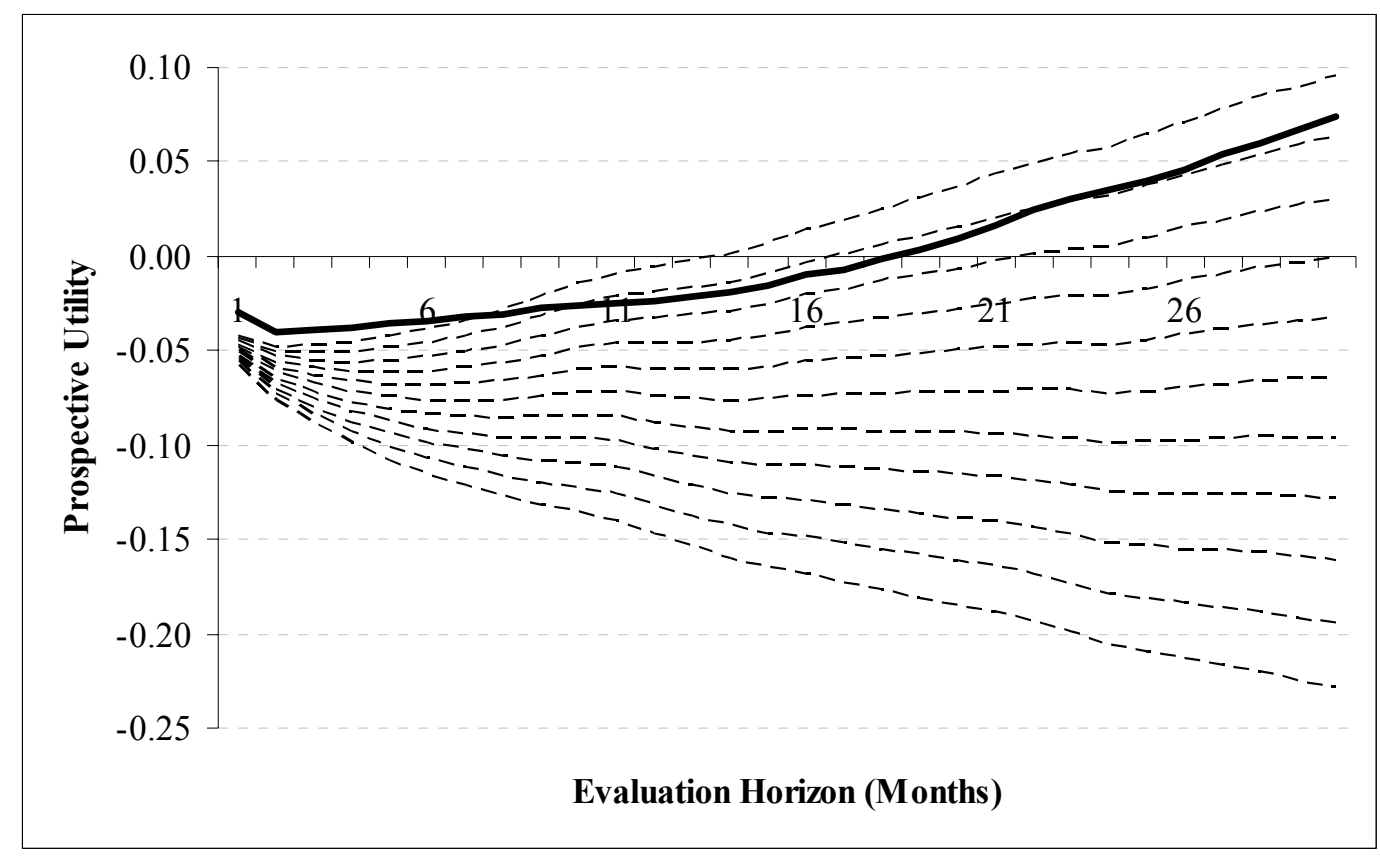


B4. Optimal portfolio allocation and implied momentum premium

Panel (A) shows prospective utility (y-axis) for different portfolio shares (x-axis) of the momentum portfolio at a 12 months evaluation horizon. The lines correspond to transaction costs ranging from zero to ten percent p.a. The remaining portfolio share is allocated to the self-financing market portfolio. Panel (B) shows implied momentum premiums for evaluation horizons from one to fifteen years (no transaction costs imposed).

Panel (A)

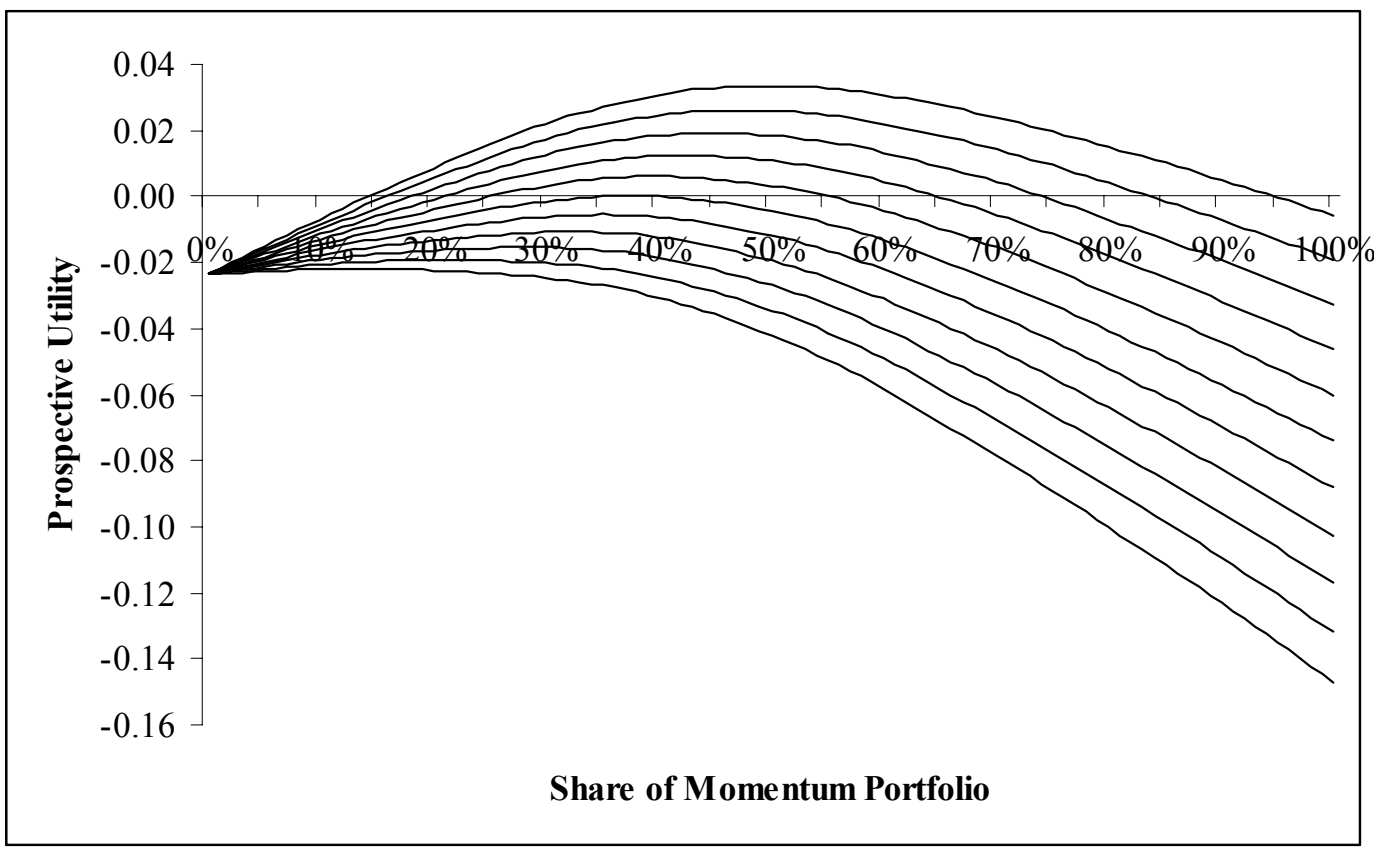

Panel (B)

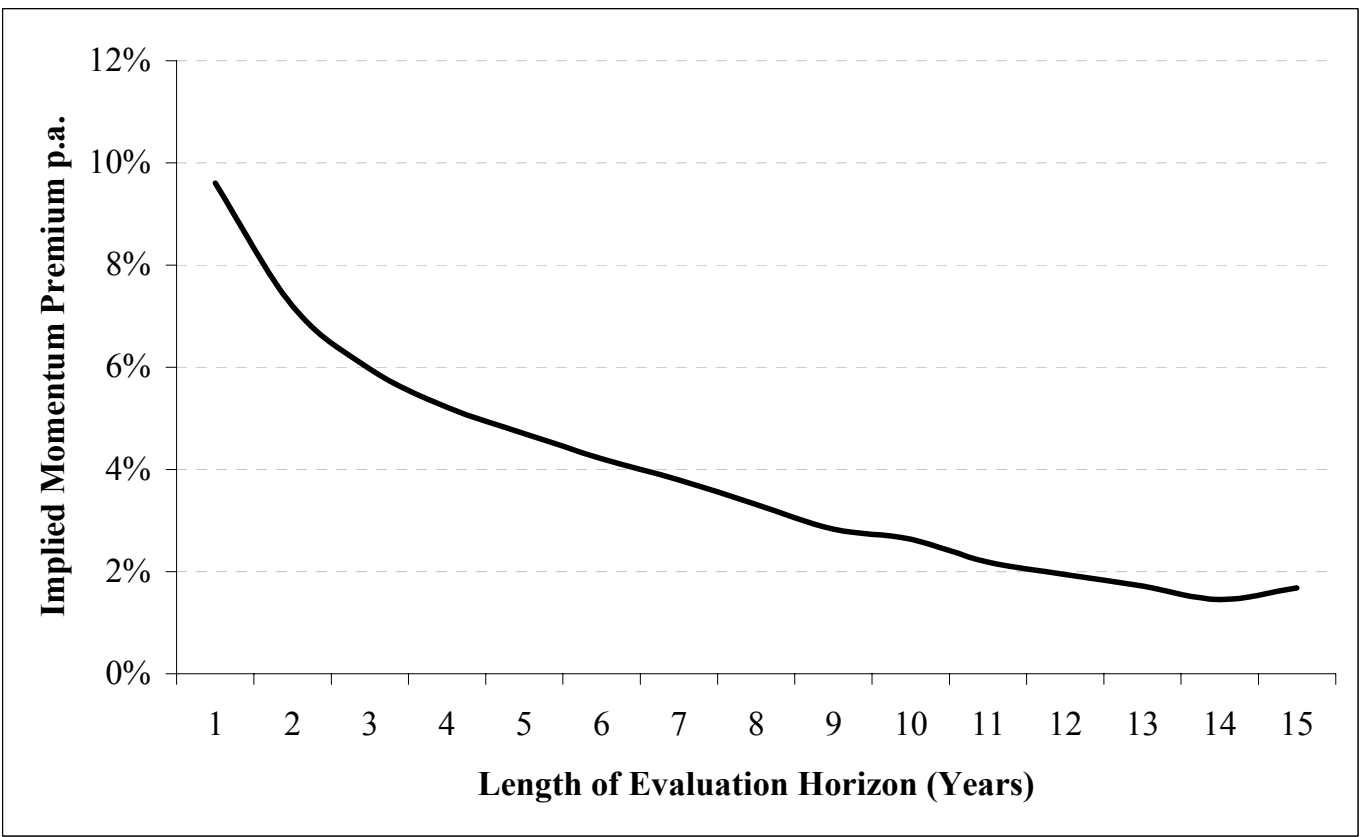

